\title{
Association between tooth size and interarch relationships in children with operated complete unilateral cleft lip and palate
}

\author{
Patrícia Bittencourt Dutra dos Santos ${ }^{1 *}$, Daniela Gamba Garib², Guilherme Janson ${ }^{3}$ and Vivian Helena Assis ${ }^{4}$
}

\begin{abstract}
Background: To evaluate mesiodistal tooth width of patients with UCLP comparing tooth size in different Goslon Yardstick scores and between cleft and noncleft sides.

Methods: The Department of Orthodontics at Bauru Dental School and Hospital of Rehabilitation of Craniofacial Anomalies - University of Sao Paulo. Hundred forty-four pairs of dental casts of patients with UCLP. These dental casts were divided into 3 groups: group I (patients with Goslon rating of 1 and 2), group II (Goslon rating of 3) and group III (Goslon rating of 4 and 5). The control group consisted of 40 pairs of dental casts of noncleft Class I patients at the same age range. Mesiodistal width of maxillary permanent central incisors, lateral incisors and first molars were measured using a digital caliper. Intergroup comparisons were performed using ANOVA followed by Tukey tests. T tests were used to compare tooth size between cleft and noncleft sides $(p<0.05)$.

Results: Differences for tooth size were observed between individuals with different Goslon Yardstik scores. Mesiodistal widths of maxillary central incisors in subjects of Group III were significantly smaller compared to Group I and to the control group. The lateral incisors at the cleft side were smaller than the antimere.

Conclusions: Mesiodistal tooth size was smaller in poor Goslon yardstick scores. Cleft and noncleft sides demonstrated similar maxillary tooth size except for the lateral incisor.
\end{abstract}

Keywords: Cleft lip; Cleft palate; Tooth size

\section{Background}

Cleft patients have considerably more dental anomalies than non-cleft patients [1]. Certain key genetic disturbances have been implicated in both dental anomalies and clefting, suggesting a shared genetic etiology in some cases $[2,3]$. Among many dental anomalies reported in CLP patients, small tooth size is frequently reported [3-6]. Besides reduced crown size, cleft patients demonstrated simplified crown morphology and malformed teeth [3]. Sabóia et al. [7] hypothesize that tooth size reductions may be part of the oral cleft phenotypic spectrum.

Foster and Lavelle [8] reported that most permanent teeth are smaller in cleft patients compared with noncleft individuals. On the other hand, the investigation of Peterka and Mullerova [9] revealed no significant

\footnotetext{
* Correspondence: pati_bittencourt@hotmail.com

1 Department of Orthodontics, State University of Rio Grande do Norte,

Caicó, RN, Brazil

Full list of author information is available at the end of the article
}

dimensional differences between mesiodistal widths of individuals with cleft lip and palate (CLP, isolated cleft palate and complete unilateral cleft lip and palate (UCLP)) and non-cleft subjects, with the exception of central incisors for males and second molars for females which were smaller in individuals with CLP [10]. Sabóia et al. [7] found smaller tooth size for canines, second premolars and first molars in the maxillary arch, and for incisors and second premolars in the mandibular arch. However, these previous studies' samples included all types of clefts (cleft lip (CL), cleft lip and palate (CLP), and cleft palate $(\mathrm{CP})$ ). Considering that $\mathrm{CL} / \mathrm{CLP}$ and $\mathrm{CP}$ have different etiological background, it is important to evaluate tooth size in each type of cleft separately. Additionally, no previous study investigated whether crown size can affect interarch sagittal relationship in patients with UCLP.

\section{空

(c) 2015 dos Santos et al.; licensee Springer. This is an Open Access article distributed under the terms of the Creative Commons Attribution License (http://creativecommons.org/licenses/by/4.0), which permits unrestricted use, distribution, and reproduction in any medium, provided the original work is properly credited. 
Therefore, the aim of this study was to evaluate mesiodistal tooth width of permanent teeth in patients with complete unilateral cleft lip and palate, by comparing tooth size in different GOSLON Yardstick scores and between cleft and non-cleft sides.

\section{Methods}

The sample size for each group was calculated based on an alpha significance level of 0.05 and a beta of 0.2 to achieve $80 \%$ of power to detect a mean difference of $0.94 \mathrm{~mm}$ in central incisor size with a $0.6 \mathrm{~mm}$ of estimated standard deviation [10]. The sample size calculation showed that 7 patients in each group were needed, and to increase the power even more, it was decided to select 32 patients for groups at least.

This project was approved by the Ethical Committee of the Bauru Dental School. Patient records were anonymized and de-identified prior to analysis. A study sample of 104 Brazilian-Caucasian patients with unilateral complete cleft lip and palate rehabilitated in a single center was retrospectively selected at Hospital of Rehabilitation of Craniofacial Anomalies. A control group of 40 dental casts of non-cleft Class I patients was selected from the growth study center at Bauru Dental School, matched by age and sex with the study sample. The inclusion criteria of the study sample were patients with complete unilateral cleft lip and palate filed at the Hospital from 1999 to 2011, without associated syndromes, with adequate dental casts taken between 8 and 10 years of age available, history of lip repair performed in the first year of life, and palate repair within the second year of life. The primary surgeries had been carried out by five different surgeons using the Millard technique for lip repair and the Van Langenbeck technique for palate repair.
The study sample was divided into three groups according to the GOSLON Yardstick index by a single examiner:

Group I: 35 patients with GOSLON Yardstick index of 1 and 2 (13 females and 22 males);

Group II: 32 patients with GOSLON Yardstick index of 3 (8 females and 24 males);

Group III: 37 patients with GOSLON Yardstick index of 4 and 5 ( 11 females and 26 males).

Mesiodistal crown width of maxillary permanent central incisors, lateral incisors, and first molars on both arch sides were measured using a digital caliper (Mitutoyo Corporation, Tokyo, Japan) directly on the dental casts by a single examiner (Figure 1). On the cleft side, only the maxillary lateral incisor distal to the cleft was measured. Teeth with interproximal caries or restorations were not considered.

\section{Error study}

In order to assess the study error, measurements of 30 dental casts were repeated by the same operator, one month after the first evaluation. Random and systematic errors were assessed using Dahlberg's formula and dependent $t$-tests, respectively.

\section{Statistical analyses}

Normal distribution was evaluated with KolmogorovSmirnov tests. Comparisons between male and female and between cleft and non-cleft sides were performed with $t$-tests. Comparison between the experimental groups and the control group was performed with one-way analysis of variance (ANOVA), followed by Tukey tests. Results were considered significant at $P<0.05$. The statistical tests were

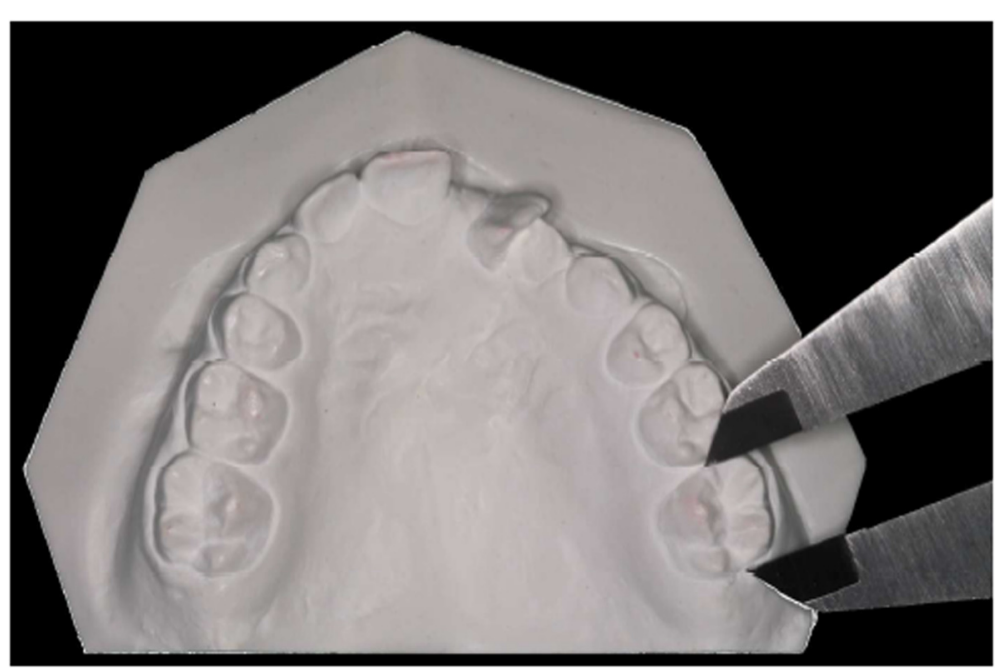

Figure 1 Measurements of crown size in the maxillary arch. 
Table 1 Systematic and casual errors (dependent $\boldsymbol{t}$-tests and Dahlberg's formula)

\begin{tabular}{|c|c|c|c|c|c|c|}
\hline \multirow[t]{3}{*}{$\begin{array}{l}\text { Mesiodistal } \\
\text { crown diameter }\end{array}$} & \multirow{2}{*}{\multicolumn{2}{|c|}{$\begin{array}{l}\begin{array}{l}\text { First } \\
\text { measurement }\end{array} \\
n=30\end{array}$}} & \multirow{2}{*}{\multicolumn{2}{|c|}{$\begin{array}{l}\begin{array}{l}\text { Second } \\
\text { measurement }\end{array} \\
n=30\end{array}$}} & \multirow[t]{3}{*}{$P$} & \multirow[t]{3}{*}{ Dahlberg } \\
\hline & & & & & & \\
\hline & Mean & SD & Mean & SD & & \\
\hline Right central incisor & 8.39 & 0.81 & 8.46 & 0.85 & 0.067 & 0.13 \\
\hline Left central incisor & 8.32 & 0.01 & 8.37 & 0.55 & 0.090 & 0.10 \\
\hline Right lateral incisor & 6,83 & 0.68 & 6.90 & 0.74 & 0.469 & 0.22 \\
\hline Left lateral incisor & 6.46 & 00.1 & 6.44 & 0,64 & 0.667 & 1.16 \\
\hline Right first molar & 10.12 & 00.1 & 10.07 & 0.68 & 0.540 & 0.29 \\
\hline Left first molar & 9.92 & 00.1 & 10.00 & 0.62 & 0.240 & 0.26 \\
\hline
\end{tabular}

performed with SPSS 7.0 for Windows (SPSS Inc., Chicago, IL, USA).

\section{Results}

Results of the error study are shown in Table 1. There were no statistically significant systematic errors and the random errors were within acceptable range.

In patients with UCLP, there was no difference in tooth size between males and females (Table 2). Crown width of the maxillary central incisors in subjects of Group III was significantly smaller than that of Group I and the control group (Table 3).

The maxillary lateral incisor was smaller on the cleft side (Table 4).

\section{Discussion}

It is recognized that poor growth of the maxillary region is related to the effects of primary repair surgery [11], and this is of particular concern for the orthodontist who must correct dentofacial discrepancies during early adolescence. Although those patients who have displayed favorable facial growth may require only relatively routine orthodontic treatment, patients with unfavorable facial growth often need orthognathic surgery for complete correction of dentofacial discrepancies [11]. In our study, all primary plastic surgeries were performed using the same surgical protocol regarding techniques, timing, and sequence. It is important once anteroposterior relationship can be influenced not only by surgery but by surgeon too $[12,13]$.

Table 2 Intergroup comparison between mesiodistal widths of permanent teeth between the female and male cleft patients ( $t$ test)

\begin{tabular}{llll}
\hline $\begin{array}{l}\text { Mesiodistal } \\
\begin{array}{l}\text { crown } \\
\text { diameter }\end{array}\end{array}$ & $\begin{array}{l}\text { Female cleft } \\
\text { Mean (SD) }\end{array}$ & $\begin{array}{l}\text { Male cleft } \\
\text { Mean (SD) }\end{array}$ & $\boldsymbol{P}$ \\
\hline Central incisor & $8.39(0.75)$ & $8.54(0.65)$ & 0.089 \\
Lateral incisor & $6.52(0.71)$ & $6.57(0.65)$ & 0.615 \\
Molar & $9.97(0.56)$ & $10.06(0.62)$ & 0.246 \\
\hline
\end{tabular}

Table 3 Intergroup comparison of maxillary tooth size between cleft and non-cleft groups (ANOVA followed by Tukey tests)

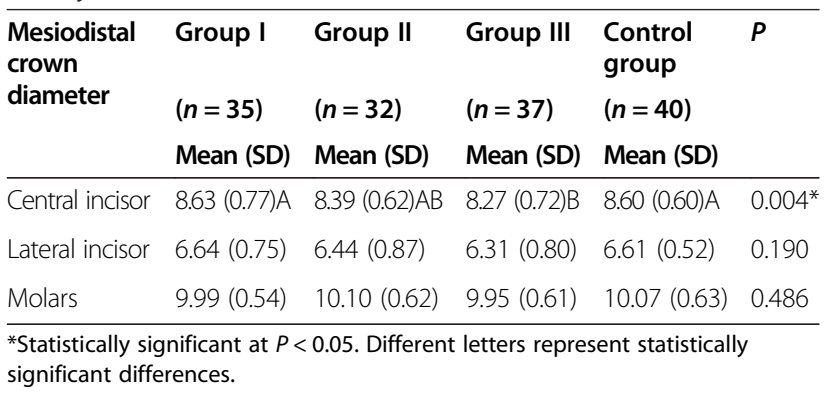

The GOSLON Yardstick has been shown to be a robust measurement tool with a high degree of reliability and reproducibility and has proven useful for longitudinal assessment of dental arch relationship [14]. Application of the Yardstick is simple and fast, requiring no specialized or expensive equipment. It does not involve application of precise and detailed criteria but relies on a simple method of judgment. The simplicity is its inherent strength, and its longitudinal robustness makes it a valuable tool. The Yardstick considers clinically important variables in all three planes of space and allows ranking of dental casts in order of difficulty to achieve a favorable outcome [15-17]. For this reason, GOSLON Yardstick was used in this study.

No significant intersex difference was found for tooth size in patients with UCLP (Table 2). Previous reports have shown no differences for tooth dimensions between males and females in patients without oral clefts [10,18-20]. Conversely, some authors reported larger teeth in males [7,21-23] as well as in females with oral clefts [8]. Saboia et al. [7] reported that combined mesiodistal widths were consistently smaller in females with oral cleft when compared to males. However, this last study included all types of clefts (CL, CLP, and CP). Rawashdeh et al. [23] found larger teeth in males with UCLP when compared to females, except for maxillary second premolar and mandibular first premolar on the cleft side.

To our knowledge, this study is the first attempt to evaluate mesiodistal tooth size in patients with UCLP

Table 4 Intergroup comparison between mesiodistal widths of permanent teeth between the cleft and non-cleft sides in the UCLP patients (ANOVA followed by Tukey tests)

\begin{tabular}{lllll}
\hline $\begin{array}{l}\text { Mesiodistal } \\
\text { crown } \\
\text { diameter }\end{array}$ & $\begin{array}{l}\text { Cleft side } \\
\text { Mean (SD) }\end{array}$ & $\begin{array}{l}\text { Non-cleft side } \\
\text { Mean (SD) }\end{array}$ & $\begin{array}{l}\text { Control group } \\
\text { Mean (SD) }\end{array}$ & $\boldsymbol{P}$ \\
\hline Central incisor & $8.36(0.66)$ & $8.45(0.79)$ & $8.60(0.60)$ & 0.088 \\
Lateral incisor & $5.68(0.51) \mathrm{A}$ & $6.84(0.65) \mathrm{B}$ & $6.61(0.52) \mathrm{B}$ & $0.000^{*}$ \\
Molar & $10.04(0.61)$ & $9.99(0.58)$ & $10.07(0.63)$ & 0.676 \\
\hline
\end{tabular}

*Statistically significant at $P<0.05$. Different letters represent statistically significant differences. 
with different GOSLON Yardstick scores. The hypothesis is that tooth size could be associated with interarch sagittal relationship. Differences were found for tooth size between patients with different GOSLON Yardistick scores (Table 3). This confirms that the maxillomandibular anteroposterior discrepancy is not the only factor related to GOSLON Yardstick scores. Mesiodistal sizes of maxillary teeth were different in extreme GOSLON Yardstick scores.

The findings indicated that the maxillary central incisors were smaller in Group III as compared to Group I and to the control group (Table 3). The difference indicated a tendency for smaller tooth size in patients with UCLP compared to non-cleft patients and patients with a mild GOSLON score. Foster and Lavelle [8] found that the maxillary teeth of complete UCLP patients were significantly smaller compared to non-cleft controls. On the other hand, Peterka and Mullerova [9] found no differences between mesiodistal tooth widths of individuals with UCLP and a control group. Another study including all cleft types (CL, CLP, and CP) found that maxillary canines and first molars were significantly reduced in size in CLP and CP groups compared to non-cleft subjects [7]. It seems that despite some controversy in this issue, the tendency is for cleft patients to present smaller mesiodistal tooth sizes.

When cleft and non-cleft sides were compared, no differences were observed for permanent central incisors and maxillary first molars. Nevertheless, the maxillary lateral incisor mesiodistal dimension was $1.2 \mathrm{~mm}$ smaller on the cleft side compared to the non-cleft side (Table 4). This result is comparable to the published data of Rawashdeh and Bakir [23] showing that the maxillary lateral incisor was statistically significantly smaller on the cleft side. Sofaer [24] and Werner and Harris [3] also demonstrated statistically significant levels of asymmetry occurring between the cleft and non-cleft sides for mesiodistal size of maxillary lateral and central incisors, respectively. According to Sofaer [24], this generalized developmental instability can, to some extent, be genetically controlled, because patients with positive family histories showed some signs of greater asymmetry than those with negative family histories.

Boehn [25] found significant antimere differences in the size of the maxillary permanent incisors in patients with cleft lip and palate [23], suggesting that cleft had a local influence on tooth size. The reason for smaller maxillary lateral incisor on the cleft side in complete UCLP is probably its double embryonic origin [25-28]. Lateral incisor located distal to the alveolar cleft is in fact 'half of a tooth' [25-28].

Because patients with poor GOSLON Yardstick scores seem to have reduced tooth size, the orthodontist may leave spaces for composite rehabilitation, to improve sagittal relationship correction. Individual tooth dimensions are important in the clinical assessment of proportions and ratios. Orthodontists aim for an esthetically pleasing dental and facial appearance with a good functional occlusion. To reach these clinical goals, the dentition has to be in proportion; this is important not only from an esthetic standpoint but also occlusally [29].

\section{Conclusions}

Maxillary mesiodistal tooth size was inversely associated with GOSLON Yardstick scores. Similar tooth sizes were found for maxillary teeth at the cleft and non-cleft sides with the exception for the maxillary lateral incisor that was smaller on the cleft side.

\section{Competing interests}

The authors declare that they have no competing interests.

\section{Authors' contributions}

PBDS: selected patients, made measurements, participated in the design of the study, performed the statistical analysis and drafted the manuscript. DGG: conceived of the study and participated in its design and coordination and helped to draft the manuscript. GJ: helped to draft the manuscript, revising it critically for important intellectual content. VHA: selected patients and made measurements. All authors read and approved the final manuscript.

\section{Author details}

${ }^{1}$ Department of Orthodontics, State University of Rio Grande do Norte, Caicó, RN, Brazil. ²Department of Orthodontics, Hospital of Rehabilitation of Craniofacial Anomalies, Bauru Dental School, University of São Paulo, Bauru, São Paulo, Brazil. ${ }^{3}$ Department of Orthodontics, Bauru Dental School, University of São Paulo, Bauru, São Paulo, Brazil. ${ }^{4}$ Hospital of Rehabilitation of Craniofacial Anomalies, Bauru Dental School, Bauru, São Paulo, Brazil.

Received: 13 October 2014 Accepted: 5 January 2015

Published online: 30 May 2015

\section{References}

1. Letra A, Menezes R, Granjeiro JM, Vieira AR. Defining subphenotypes for oral clefts based on dental development. J Dent Res. 2007;86(10):986-91.

2. Dentino KM, Peck S, Garib DG. Is missing maxillary lateral incisor in complete cleft lip and palate a product of genetics or local environment? Angle Orthod. 2012;82(6):959-63. doi:10.2319/012012-49.1.

3. Werner SP, Harris EF. Odontometrics of the permanent teeth in cleft lip and palate: systemic size reduction and amplified asymmetry. Cleft Palate J. 1989:26(1):36-41.

4. Wangsrimongkol T, Manosudprasit M, Pisek P, Chittiwatanapong N Prevalence and types of dental anomaly in a Thai non-syndromic oral cleft sample. J Med Assoc Thail. 2013;96 Suppl 4:S25-35.

5. Al Jamal GA, Hazza'a AM, Rawashdeh MA. Prevalence of dental anomalies in a population of cleft lip and palate patients. Cleft Palate Craniofac J. 2010:47(4):413-20. doi:10.1597/08-275.1.

6. Eslami N, Majidi MR, Aliakbarian M, Hasanzadeh N. Prevalence of dental anomalies in patients with cleft lip and palate. J Craniofac Surg. 2013;24(5):1695-8. doi:10.1097/SCS.0b013e3182801bc8.

7. de Saboia TM, Kuchler EC, Tannure PN, Rey AC, Granjeiro JM, de Castro CM et al. Mesio-distal and buccal-lingual tooth dimensions are part of the cleft spectrum: a pilot for future genetic studies. Cleft Palate Craniofac J. 2013;50(6):678-83. doi:10.1597/11-228.

8. Foster TD, Lavelle CL. The size of the dentition in complete cleft lip and palate. Cleft Palate J. 1971:8:177-84.

9. Peterka M, Mullerova Z. Tooth size in children with cleft lip and palate. Cleft Palate J. 1983;20(4):307-13

10. Lewis BR, Stern MR, Willmot DR. Maxillary anterior tooth size and arch dimensions in unilateral cleft lip and palate. Cleft Palate Craniofac J. 2008;45(6):639-46. doi:10.1597/07-078.1. 
11. Mars M, Houston WJ. A preliminary study of facial growth and morphology in unoperated male unilateral cleft lip and palate subjects over 13 years of age. Cleft Palate J. 1990;27(1):7-10.

12. Ross RB. The clinical implications of facial growth in cleft lip and palate. Cleft Palate J. 1970;7:37-47.

13. Normando AD, da Silva Filho OG, Capelozza FL. Influence of surgery on maxillary growth in cleft lip and/or palate patients. J Craniomaxillofac Surg. 1992;20(3):111-8.

14. Mars M, Plint DA, Houston WJ, Bergland O, Semb G. The Goslon Yardstick: a new system of assessing dental arch relationships in children with unilateral clefts of the lip and palate. Cleft Palate J. 1987;24(4):314-22.

15. Chan KT, Hayes C, Shusterman S, Mulliken JB, Will LA. The effects of active infant orthopedics on occlusal relationships in unilateral complete cleft lip and palate. Cleft Palate Craniofac J. 2003;40(5):511-7. doi:10.1597/1545-1569(2003)040<0511:TEOAIO>2.0.CO;2.

16. Mars M, Batra P, Worrell E. Complete unilateral cleft lip and palate: validity of the five-year index and the Goslon yardstick in predicting long-term dental arch relationships. Cleft Palate Craniofac J. 2006;43(5):557-62. doi:10.1597/05-074.

17. Garib DG, Santos PB, Janson G, Assis VH, de Paula Leite Battisti M. Association between dental arch widths and interarch relationships in children with operated unilateral complete cleft lip and palate. Cleft Palate Craniofac J. 2013. doi:10.1597/12-171.

18. Araujo E, Souki M. Bolton anterior tooth size discrepancies among different malocclusion groups. Angle Orthod. 2003;73(3):307-13. doi:10.1043/0003-3219(2003)073<0307:BATSDA>2.0.CO;2.

19. Basaran G, Selek M, Hamamci O, Akkus Z. Intermaxillary bolton tooth size discrepancies among different malocclusion groups. Angle Orthod. 2006;76(1):26-30. doi:10.1043/0003-3219(2006)076[0026:IBTSDA]2.0.CO;2.

20. Nie Q, Lin J. Comparison of intermaxillary tooth size discrepancies among different malocclusion groups. Am J Orthod Dentofacial Orthop. 1999;116(5):539-44.

21. Lavelle CL. Maxillary and mandibular tooth size in different racial groups and in different occlusal categories. Am J Orthod. 1972;61(1):29-37.

22. Bishara SE, Jakobsen JR, Treder JE, Stasi MJ. Changes in the maxillary and mandibular tooth size-arch length relationship from early adolescence to early adulthood. A longitudial study. Am J Orthod Dentofacial Orthop. 1989;95(1):46-59.

23. Rawashdeh MA, Bakir IF. The crown size and sexual dimorphism of permanent teeth in Jordanian cleft lip and palate patients. Cleft Palate Craniofac J. 2007;44(2):155-62. doi:10.1597/05-197.1.

24. Sofaer JA. Human tooth-size asymmetry in cleft lip with or without cleft palate. Arch Oral Biol. 1979;24(2):141-6.

25. Boehn A. Dental anomalies in harelip and cleft palate. Acta Odontol Scand 1963;21(SUPPL38):1-109.

26. Hovorakova M, Lesot H, Peterkova R, Peterka M. Origin of the deciduous upper lateral incisor and its clinical aspects. J Dent Res. 2006;85(2):167-71.

27. Yatabe MS, Garib DG, Janson G, Poletto RS, Ozawa TO. Is the presence of Simonart's band in patients with complete unilateral cleft lip and palate associated with the prevalence of missing maxillary lateral incisors? Am J Orthod Dentofacial Orthop. 2013;144(5):649-53. doi:10.1016/ j.ajodo.2013.06.018.

28. Sulik K. Orofacial embryogenesis: a framework for understanding clefting sites. In: Fonseca RJMR, Turvey TA, editors. Oral and maxillofacial surgery. Philadelphia: Saunders; 2009. p. 711.

29. Bolton W. The clinical application of a tooth-size analysis. Am J Orthod Dentofacial Orthop. 1962;48:504-29.

\section{Submit your manuscript to a SpringerOpen ${ }^{\circ}$ journal and benefit from:}

- Convenient online submission

- Rigorous peer review

- Immediate publication on acceptance

- Open access: articles freely available online

- High visibility within the field

- Retaining the copyright to your article

Submit your next manuscript at $>$ springeropen.com 